\title{
SUBSTITUIÇ̃̃o DE NITRATO DE POTÁSSIO (PA) POR SALITRE POTÁSSICO NO PREPARO DE MEIO DE CULTURA DE TECIDOS VEGETAIS ESTERILIZADO COM HIPOCLORITO DE SÓDIO ${ }^{1}$
}

\author{
Potassium nitrate substitution for potassic saltpetre on preparation of plant tissue culture \\ nutritive media esterilized with sodium hypochlorite
}

\author{
Juliana Martins Ribeiro ${ }^{2}$, Silvio Lopes Teixeira ${ }^{3}$
}

\begin{abstract}
RESUMO
A aquisição de nitrato de potássio PA, para qualquer finalidade, depende de autorização do Ministério da Defesa, o que resulta em dificuldades na sua aquisição. Com a finalidade de estudar a possibilidade da substituição desse reagente por outro produto encontrado livremente no comércio, foi conduzido um experimento onde se testaram várias concentrações de salitre potássico em comparação com o nitrato de potássio PA, como componente dos sais de MS. Utilizou-se o produto granulado MURER ${ }^{\circledR}$ nas seguintes concentrações $\left(\mathrm{g} \mathrm{L}^{-1}\right)$ : a) 7,0; b) 7,4; c) 7,8; d) 8,2. Foi adicionado um tratamento-controle, com o $\mathrm{KNO}_{3} \mathrm{PA}_{\text {, conforme }}$ aparece nos sais de MS $\left(1,9 \mathrm{~g} \mathrm{~L}^{-1}\right)$, sendo a espécie testada à fáfia, a partir de segmentos nodais. $\mathrm{O}$ meio de cultura constituiu-se dos sais de MS, vitaminas de White, $30 \mathrm{~g} \mathrm{~L}^{-1}$ sacarose, $2,0 \mathrm{mg} \mathrm{L}^{-1}$ ácido indol butírico, 2,0 mg L $\mathrm{m}^{-1}$ ácido naftalenoacético, 2,0 mg L

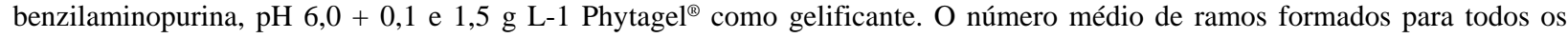
tratamentos foi inferior ao do tratamento-controle; mas, em compensação, o comprimento médio deles foi superior, também em todos os tratamentos, sendo que o comprimento total de ramos na menor concentração de salitre, atingiu $17,0 \mathrm{~cm}$, enquanto no tratamentocontrole foi de $12,6 \mathrm{~cm}$. A média da biomassa seca foi de $68,3 \mathrm{mg}$ para a menor concentração de salitre e de $50,0 \mathrm{mg}$ para o tratamentocontrole. A análise dos resultados indicou ser vantajosa a substituição do nitrato de potássio PA pelo salitre potássico.
\end{abstract}

Termos para indexação: Pfaffia glomerata, micropropagação, formulação de sais minerais, reagentes PA.

\begin{abstract}
The acquisition of potassium nitrate for any purpose, including preparation of nutritive media for micropropagation, depends on authorization from the Ministry of Defense, what turns out in difficulties in its acquisition. With the purpose of studying the possibility of replacing this component of the culture for another product found freely in the market, an experiment was carried out, where several concentrations of potassic saltpetre were tried, in comparison to the chemically pure potassium nitrate, as a component of the MS salts formulation. The commercial granulated product MURER ${ }^{\circledR}$ was used in the following $\left(\mathrm{g} \mathrm{L}^{-1}\right)$ : a) 7,$\left.0 ; \mathrm{b}\right)$ 7,4 ; c) 7,8; d) 8,2; and e) chemically pure potassium nitrate (control-treatment) as it appears in the MS salts, or $1,9 \mathrm{~g} \mathrm{~L}^{-1} \mathrm{Fáfia} \mathrm{was}$ tested, starting from nodal segments. The basal nutrient medium comprised the MS salts, White vitamins, $30 \mathrm{~g} \mathrm{~L}-1 \mathrm{sucrose}, 2.0 \mathrm{mg}$ L-1 indol butyric acid, $2.0 \mathrm{mg} \mathrm{L}-1$ naftaleneacetic acid, $2.0 \mathrm{mg} \mathrm{L}-1$ benzilaminopurine, pH $6.0+0.1$ and $1.5 \mathrm{~g} \mathrm{~L}-1$ Phytagel ${ }^{\circledR}$ as the gelling agent. The number of branches formed in all concentrations of potassic saltpetre was lower than those ones in the control treatment; however, their lengths were higher. The mean length of branches in the treatment with the smallest potassic saltpetre concentration, reached $17.0 \mathrm{~cm}$ in length, while in the control-treatment it was $12,6 \mathrm{~cm}$. The dry biomass weight reached $68.3 \mathrm{mg}$ for the smallest potassic saltpetre concentration, but only $50,0 \mathrm{mg}$ for the control treatment. The results indicated to be advantageous the substitution of the chemically pure potassium nitrate for the potassic saltpeter, when either shoot elongation or biomass production is desired, being the nutrient medium sterilized with sodium hipoclorite. However, when a faster multiplication rate is the main objective, the nutrient medium should be prepared with chemically pure potassium nitrate.
\end{abstract}

Index terms: Pfaffia glomerata, micropropagation, minerals salts preparation, PA reagents.

(Recebido em 2 de julho de 2007 e aprovado em 19 de fevereiro de 2008)

\section{INTRODUÇÃO}

O potássio é um macronutriente essencial envolvido na manutenção do estado hídrico da planta, abertura e fechamento de estômatos, turgescência das células vegetais, acúmulo e translocação de carboibratos recém- formados, formação de raízes e amadurecimento dos frutos (FAQUIN, 1994; MALAVOLTA et al., 1997; TAIZ \& ZEIGER, 2004). Os principais sintomas relacionados com a deficiência de potássio são a baixa produção e a qualidade dos frutos, plantas com raízes pouco desenvolvidas, caules fracos e muito flexíveis. Devido à alta mobilidade

${ }^{1}$ Trabalho financiado pela FAPERJ, FENORTE/TECNORTE e UENF.

'Bióloga, Doutora e Produção Vegetal, Pesquisadora - Centro de Pesquisa Agropecuária do Trópico Semi-Árido - Laboratório de Biotecnologia Vegetal Embrapa Semi-Árido/CPATSA - Br 428, Km 152 - Cx. P. 23 - Zona Rural - 56300-970 - Petrolina, PE - juliana.ribeiro@cpatsa.embrapa.br

${ }^{3}$ Doutor em Botânica, Professor Adjunto - Rua Pedro Marins, 218 - Flamboyant - 28015-180 - Campos dos Goytacazes, RJ - teixeira70@yahoo.com.br 
apresentada pelo potássio, os sintomas de sua deficiência aparecem primeiro nas folhas mais velhas, na forma de queimaduras marginais (MALAVOLTA \& CROCOMO, 1982; MALAVOLTA et al., 1997). Além disso, plantas com deficiência em potássio acamam facilmente e apresentamse sensíveis à infestação por doenças (THEODORO \& MARINGONI, 2006).

O nitrato de potássio é um dos reagentes que compõem os meios de cultura de tecidos vegetais, constituindo-se da proporção mais elevada em relação aos demais reagentes, na formulação de sais de MS (MURASHIGE \& SKOOG, 1962). O reagente citado é utilizado na micropropagação como fonte de nitrogênio e potássio, sendo esses dois elementos encontrados em maiores quantidades nas plantas e responsáveis principalmente pelo crescimento das plantas e desenvolvimento de raízes, e por regular o potencial osmótico das células vegetais, respectivamente.

A regra geral, no preparo de meios de cultura de tecidos vegetais, é a utilização de reagentes PA (proanalisis), por conterem quantidades muito reduzidas de impurezas, minimizando possíveis influências negativas de outras substâncias químicas na reação das plantas cultivadas, as quais seriam encontradas em reagentes com menor grau de pureza. Como o nitrato de potássio pode ser utilizado na produção de explosivos, sua aquisição para qualquer finalidade, inclusive para o preparo de meios nutritivos para micropropagação, depende de autorização do Ministério da Defesa, o que resulta em dificuldades burocráticas na sua aquisição. Como o produto comercial apresenta custo mais baixo em relação ao produto do tipo "PA", essa é uma vantagem adicional que justifica a sua utilização no preparo de meios de cultura, em pequenos laboratórios comerciais e biofábricas, mesmo que resulte em alguma desvantagem quanto à reação das plantas ao meio nutritivo.

Os autores vêm desenvolvendo um programa de pesquisa que visa a redução de custos de mudas propagadas em laboratórios de micropropagação. Entre as linhas de pesquisa em andamento estão o desenvolvimento ou o aperfeiçoamento de protocolos de propagação para espécies tropicais (TEIXEIRA et al., 2003), a esterilização química de meios de cultura (TEIXEIRA et al., 2005) e a inoculação de explantes em ambiente não estéril, utilizando o protocolo de esterilização química (TEIXEIRA \& MATTA, 2006).

Objetivou-se, no presente trabalho, estudar a possibilidade da substituição de $\mathrm{KNO}_{3} \mathrm{PA}$ por salitre potássico, no preparo de meio de cultura esterilizado com hipoclorito de sódio.

\section{MATERIAL E MÉTODOS}

O material vegetal utilizado como doador de explantes foi proveniente de cultura-estoque mantida in vitro, oriunda do acesso COVP de Pfaffia glomerata L. do Laboratório de Cultura de Tecidos Vegetais, do Setor de Fitotecnia do Centro de Ciências e Tecnologias Agropecuárias, da Universidade Estadual do Norte Fluminense. As culturas-estoque foram mantidas por passagens de 30 dias, sob fotoperíodo de 16 horas e iluminância de $60 \mu \mathrm{mol} \mathrm{m} \mathrm{m}^{-2} \mathrm{~s}^{-1} \mathrm{e}$ temperatura de $27 \pm$ $2{ }^{\circ} \mathrm{C}$, em tubos de ensaio de $25 \times 150 \mathrm{~mm}$ contendo meio de cultura composto pelos sais MS (MURASHIGE \& SKOOG, 1962), vitaminas White (WHITE, 1943), $100 \mathrm{mg} \mathrm{L}^{-1}$ de iinositol, $30 \mathrm{~g} \mathrm{~L}^{-1}$ de sacarose, $2 \mathrm{mg} \mathrm{L}^{-1}$ de AIA, $2 \mathrm{mg} \mathrm{L}^{-1} \mathrm{de}$ AIB, $2 \mathrm{mg} \mathrm{L}^{-1}$ de BAP, esterilizados por autoclavagem $\left(121{ }^{\circ} \mathrm{C}, 1,05 \mathrm{~kg} \mathrm{~cm}^{2}\right.$, por 15 minutos).

Foram testadas concentrações de salitre potássico no meio nutritivo, utilizando-se o produto granulado MURER $^{\circledR}$. Ao contrário das culturas-estoque, que estavam sendo mantidas em meios nutritivos esterilizados por autoclavagem, todos os tratamentos testados na presente pesquisa foram esterilizados quimicamente com a adição de $0,01 \%$ de hipoclorito de sódio (p/v) ao meio nutritivo.

Após o uso anterior, a vidraria utilizada no preparo e no acondicionamento do meio de cultura foi lavada com detergente e enxaguada com água clorada com 0,001\% de hipoclorito de sódio e mantida em armário de aço. No momento do preparo do meio, a vidraria foi novamente enxaguada com água clorada adicionada de $0,003 \%$ de hipoclorito de sódio $(\mathrm{p} / \mathrm{v})$. Os tubos de ensaio, nos quais foi vertido o meio de cultura, foram tratados da mesma forma que as demais vidrarias, porém o enxagüe com a solução de hipoclorito de sódio foi efetuado imediatamente antes do meio de cultura ser vertido.

Após o enxagüe das vidrarias, procedeu-se ao preparo da água utilizada para completar o volume final do meio de cultura, constituindo-se de água deionizada adicionada de 0,0005\% de hipoclorito de sódio (p/v). Em cinco Erlenmeyers, cada um correspondente a um tratamento, foram adicionados, além da sacarose e Phytagel, todos os demais reagentes para o preparo dos meios de cultura, conforme Murashige \& Skoog (1962), exceto o $\mathrm{KNO}_{3}$ PA. Foram testadas as seguintes concentrações de salitre potássico: A) $7 \mathrm{~g} \mathrm{~L}^{-1}$; B) $7,4 \mathrm{~g} \mathrm{~L}^{-1}$; C) $7,8 \mathrm{~g} \mathrm{~L}^{-1}$; D) 8,2 $\mathrm{g} \mathrm{L}^{-1}$. O tratamento $\mathrm{E}$ foi preparado com $1,9 \mathrm{~g} \mathrm{~L}^{-1} \mathrm{KNO}_{3} \mathrm{PA}$, conforme as recomendações de Murashige \& Skoog (1962). Após a incorporação de todos os reagentes, adicionou-se 0,01\% de hipoclorito de sódio a cada um dos Erlenmeyers, de modo a esterilizar os meios de cultura, conforme a técnica de esterilização química desenvolvida por Teixeira et al. 
(2006), em substituição à esterilização por autoclavagem. Após 15 minutos, o pH dos meios nos diferentes Erlenmeyers foi ajustado para 6,0 $\pm 0,1$, o volume final de cada tratamento foi completado com água deionizada adicionada de $0,0005 \%$ de $\mathrm{NaClO}$, e os Erlenmeyers com os meios de cultura foram introduzidos no forno de microondas para fusão do Phytagel. Após a fusão do Phytagel, os tubos de ensaio foram enxaguados com água deionizada contendo $0,003 \%$ de hipoclorito de sódio $(\mathrm{p} / \mathrm{v})$ e neles vertido o meio de cultura.

Todas as operações iniciais de preparo do meio de cultura foram efetuadas em ambiente não estéril do laboratório. O enchimento dos tubos de ensaio com o meio de cultura foi realizado na capela de fluxo laminar, 15 minutos após o enxagüe desses com a água clorada.

Ramos de fáfia foram retirados dos tubos de ensaio nos quais estavam sendo cultivados e transferidos para placas de Petri. Com auxílio de pinças e bisturis, os ramos foram reduzidos a fragmentos de aproximadamente $1,0 \mathrm{~cm}$ de comprimento e transferidos para tubos de ensaio, contendo $20 \mathrm{~mL}$ dos meios de cultura representados pelos tratamentos. Todo esse procedimento foi realizado em capela de fluxo laminar, com a utilização de ferramentas cirúrgicas e utensílios esterilizados por autoclavagem.

Um mês após a inoculação dos explantes, houve a formação de plantas completas das quais foram coletados dados quanto ao número de ramos por cultura, comprimento dos ramos, número de culturas sobreviventes à média da biomassa seca por cultura. Para tal procedimento, as plantas foram retiradas dos tubos de ensaio, o número de ramos foi contado, o comprimento de cada ramo foi medido com uma régua graduada em milímetros. Em seguida, procedeu-se à secagem da biomassa fresca em estufa a $70{ }^{\circ} \mathrm{C}$ até atingir peso constante, para a coleta de dados em relação ao total da biomassa seca de cada tratamento.
O experimento foi conduzido em delineamento inteiramente casualizado, com 5 tratamentos e 20 repetições, sendo a unidade experimental constituída de um explante por tubo de ensaio.

\section{RESULTADOS E DISCUSSÃO}

Na Figura 1 são apresentadas as características do desenvolvimento vegetativo nos cinco tratamentos utilizados. Como pode ser observado, houve um maior desenvolvimento das plantas nos tratamentos A, B e C, entretanto, um maior número de ramos foi observado no tratamento E (controle). Além disso, observa-se um maior desenvolvimento das raízes nos tratamentos $\mathrm{A}$ e $\mathrm{B}$, quando comparados com os tratamentos C, D e E.

A Tabela 1 indica que o emprego do salitre potássico não afetou a sobrevivência das culturas, o que significa que o produto não afetou a ação esterilizante do hipoclorito de sódio, nem causou danos aos tecidos da fáfia.

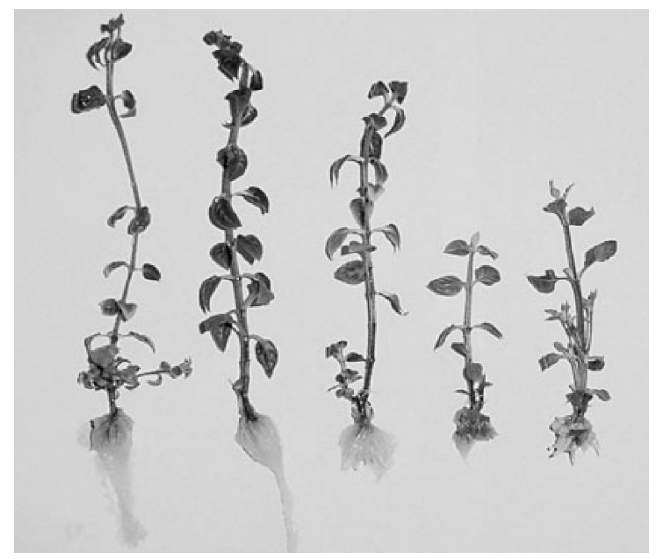

Figura 1 - Representação visual do desenvolvimento de plantas de Pfaffia glomerata com base na eficiência dos tratamentos.

Tabela 1 - Parâmetros analisados, em função da concentração de salitre potássico adicionado ao meio de cultura esterilizado com hipoclorito de sódio.

\begin{tabular}{cccccc}
\hline $\begin{array}{c}\mathrm{KNO}_{3} \\
\left(\mathrm{~g} \mathrm{~L}^{-1}\right)\end{array}$ & \multicolumn{2}{c}{ Culturas sobreviventes } & $\begin{array}{c}\text { Número médio de } \\
\text { ramos }\end{array}$ & $\begin{array}{c}\text { Comprimento médio } \\
\text { de ramos }(\mathrm{cm})\end{array}$ & $\begin{array}{c}\text { Média da biomassa } \\
\text { seca }(\mathrm{mg})\end{array}$ \\
\hline 7,0 & $18 \mathrm{a}$ & $90 \mathrm{a}$ & $2,4 \mathrm{~b}$ & $7,1 \mathrm{~b}$ & 68,3 \\
7,4 & $18 \mathrm{a}$ & $90 \mathrm{a}$ & $1,2 \mathrm{c}$ & $11,1 \mathrm{a}$ & 65,6 \\
7,8 & $19 \mathrm{a}$ & $95 \mathrm{a}$ & $2,4 \mathrm{~b}$ & $4,2 \mathrm{c}$ & 34,2 \\
8,2 & $20 \mathrm{a}$ & $100 \mathrm{a}$ & $2,7 \mathrm{~b}$ & $4,0 \mathrm{c}$ & 43,0 \\
$\mathrm{MS}(1,9)$ & $20 \mathrm{a}$ & $100 \mathrm{a}$ & $4,5 \mathrm{a}$ & $2,8 \mathrm{c}$ & 50,0 \\
\hline
\end{tabular}

Os dados acompanhados por uma mesma letra são estatisticamente iguais segundo o Teste de Tukey, com 5\% de probabilidade. 
Em relação ao número de ramos por cultura, o fato da concentração de $7,4 \mathrm{~g} \mathrm{~L}^{-1}$ de $\mathrm{KNO}_{3}$ ter apresentado média inferior tanto à concentração mais baixa do produto, quanto às mais altas, indica uma variação aleatória e não uma conseqüência da referida concentração do produto. Portanto, estatisticamente ela se iguala às demais concentrações, as quais apresentaram número médio de ramos, cerca da metade do número apresentado pelo tratamento que utilizou o $\mathrm{KNO}_{3} \mathrm{PA}$, porém com comprimentos médios de ramos variando entre uma vez e meia e quatro vezes maiores.

As duas menores concentrações de salitre potássico, embora tenham apresentado número de ramos cerca de duas vezes menor do que o tratamento com $\mathrm{KNO}_{3}$ $\mathrm{PA}$, apresentaram, porém, comprimento de ramos cerca de 3 e 4 vezes maior, respectivamente, além da tendência de favorecerem maior biomassa seca.

O comprimento médio dos ramos nos tratamentos que utilizaram salitre potássico foi superior em todos os tratamentos, sendo que o comprimento total de ramos (número médio x comprimento médio), no tratamento com a menor concentração de salitre (tratamento A), atingiu a $17,0 \mathrm{~cm}$, enquanto no tratamento-controle foi de $12,6 \mathrm{~cm}$.

$\mathrm{O}$ nitrato de potássio $\left(\mathrm{KNO}_{3}\right)$ possui $13 \%$ de $\mathrm{N}$ e $44 \%$ de $\mathrm{K}_{2} \mathrm{O}$ em sua fórmula. $\mathrm{O}$ salitre potássico $\left(\mathrm{NaNO}_{3}\right.$ $\mathrm{KNO}_{3}$ ), por sua vez, possui $15 \%$ de $\mathrm{N}$ e $14 \%$ de $\mathrm{K}_{2} \mathrm{O}$ em sua fórmula. Fazendo uma comparação entre ambos os elementos, pode-se observar que o nitrato de potássio possui mais $\mathrm{K}_{2} \mathrm{O}$ em relação ao salitre potássico, e esse último apresenta um maior teor de nitrogênio, além da presença do sódio em sua fórmula (TRANI, 2007).

Além da relação antagônica existente entre comprimento e número médio de ramos, o maior crescimento das plantas inoculadas em meio nutritivo contendo salitre potássico também pode ser atribuído ao fato de o nitrogênio estar diretamente relacionado com o crescimento vegetal, e a presença de sódio em baixos níveis na planta estimular o crescimento por meio de uma maior expansão celular (TAIZ \& ZEIGER, 2004).

O fato das plantas inoculadas em meio nutritivo, contendo nitrato de potássio, terem apresentado um maior número de ramos, quando comparadas com aquelas inoculadas em meio contendo salitre potássico também pode ser explicado pelo fato de o potássio estar diretamente envolvido com a síntese protéica, respiração e fotossíntese nas plantas (FAQUIN, 1994), fatores esses que interferem diretamente, de forma favorável, no processo de formação de brotos.

Pode-se, portanto, concluir ser vantajosa a substituição do $\mathrm{KNO}_{3} \mathrm{PA}$ pelo salitre potássico, em concentrações que podem variar entre 7,0 e 7,4 $\mathrm{g} \mathrm{L}^{-1}$, principalmente quando a prioridade for maior comprimento de ramos ou maior peso de biomassa. Todavia, quando a prioridade for taxa de multiplicação mais elevada, recomenda-se o emprego do $\mathrm{KNO}_{3} \mathrm{PA}$.

\section{CONCLUSÕES}

A substituição de $\mathrm{KNO}_{3}$ por salitre potássico no meio de cultura resulta na redução da taxa de multiplicação de Pfaffia glomerata cultivada in vitro, em meio de cultura esterilizado com hipoclorito de sódio.

A substituição de $\mathrm{KNO}_{3}$ por salitre potássico, no meio de cultura, estimula o alongamento dos ramos de Pfaffia glomerata cultivada in vitro, em meio de cultura esterilizado com hipoclorito de sódio.

A substituição de $\mathrm{KNO}_{3}$ por salitre potássico, no meio de cultura, tende a induzir aumento da biomassa de Pfaffia glomerata cultivada in vitro, em meio de cultura esterilizado com hipoclorito de sódio.

As concentrações ideais de salitre potássico a serem adicionadas ao meio de cultura, quando se deseja estimular o alongamento dos ramos ou a produção de biomassa de Pfaffia glomerata cultivada in vitro, em meio de cultura esterilizado com hipoclorito de sódio, deve variar entre 7,0 e 7,4 $\mathrm{g} \mathrm{L}^{-1}$.

Quando o objetivo for obter maior taxa de multiplicação de Pfaffia glomerata cultivada in vitro, em meio de cultura esterilizado com hipoclorito de sódio, o meio de cultura deve ser preparado com $\mathrm{KNO}_{3} \mathrm{PA}$ e não com o produto comercial .

\section{AGRADECIMENTOS}

À FENORTE/TECNORTE, FAPERJ e UENF pelo suporte financeiro.

\section{REFERÊNCIAS BIBLIOGRÁFICAS}

FAQUIN, V. Nutrição mineral de plantas. Lavras: ESALFAEPE, 1994. $227 \mathrm{p}$.

MALAVOLTA, E.; CROCOMO, O. J. O potássio e a planta. In: YAMADA, T.; IGUE, K.; MUZILLI, O.; USHERWOOD, N. R. (Eds.). O potássio na agricultura brasileira. Piracicaba: Instituto da Potassa \& Fosfato; Instituto Internacional da Potassa, 1982. p. 95-162.

MALAVOLTA, E.; VITTI, G. C.; OLIVEIRA, S. A. Avaliação do estado nutricional das plantas: princípios e aplicações. Piracicaba: Potafós, 1997. 319 p. 
MURASHIGE, T.; SKOOG, F. A revised medium for rapid growth and bioassays with tobacco tissue cultures. Physiologia Plantarum, Copenhagen, v. 15, p. 473-497, 1962.

TAIZ, L.; ZEIGER, E. Fisiologia vegetal. 3. ed. Porto Alegre: Artmed, 2004. 719 p.

TEIXEIRA, S. L.; ALMEIDA, R. F.; TEIXEIRA, M. T.; RODRIGUES, J. S. Desenvolvimento de técnicas de clonagem de espécies tropicais, para produção de mudas em larga escala na biofábrica da FENORTE, em Campos dos Goytacazes, RJ: relatório de pesquisa. Campos dos Goytacazes: UENF, 2003. 10 p.

TEIXEIRA, S. L.; MATTA, I. G. Inoculação de explantes em meios de cultura de tecidos vegetais em ambiente não estéril: relatório de pesquisa. Campos dos Goytacazes: UENF, 2006. 12 p.

TEIXEIRA, S. L.; RIBEIRO, J. M.; TEIXEIRA, M. T. Esterilização química de meios de cultura: relatório de pesquisa. Campos dos Goytacazes: UENF, 2005. 11 p.
TEIXEIRA, S. L.; RIBEIRO, J. M.; TEIXEIRA, M. T. Influence of $\mathrm{NaClO}$ on nutrient medium sterilization and on pineapple (Ananas comosus cv Smooth cayenne) behavior. Plant Cell, Tissue and Organic Culture, Dordrecht, v. 86, p. 75-378, 2006.

THEODORO, G. de F.; MARINGONI, A. C. Efeito de doses de potássio na severidade da murcha-decurtobacterium em cultivares de feijoeiro comum. Summa Phytopathology, Botucatu, v. 32, n. 2, p. 139146, 2006.

TRANI, P. E. Calagem e adubação para hortaliças sob cultivo protegido. Disponível em: <http:// Lwww.infobibos.com/Artigos/2007 $1 / \mathrm{cp} / \mathrm{index}$ htm Acesso em: 10 fev. 2007.

WHITE, P. R. Nutrient deficiency studies and an improved inorganic nutrient medium for cultivation of excised tomato roots. Growth, [S.1.], v. 7, p. 53-65, 1943. 